\title{
F2-Isoprostanes as Novel Biomarkers for Type 2 Diabetes: a Review
}

\author{
Subramanian Kaviarasan ${ }^{1}$, Sekaran Muniandy ${ }^{2, *}$, Rajes Qvist ${ }^{1}$, and Ikram S. Ismail ${ }^{1}$ \\ ${ }^{1}$ Department of Medicine, University of Malaya Medical Center, University of Malaya, \\ 50603 Kuala Lumpur, Malaysia \\ ${ }^{2}$ Department of Molecular Medicine, Faculty of Medicine, University of Malaya, 50603 Kuala Lumpur, Malaysia
}

Received 16 December, 2008; Accepted 16 January, 2009

\begin{abstract}
Summary Oxidative stress (OS) has been implicated as one of the major underlying mechanisms behind many acute and chronic diseases. However, the measurement of free radicals or their end products is complicated. Isoprostanes, derived from the non-enzymatic peroxidation of arachidonic acid are now considered to be reliable biomarkers of oxidant stress in the human body. Isoprostanes are involved in many of the human diseases such as type 2 diabetes. In type 2 diabetes elevated levels of $F_{2}$-Isoprostanes $\left(F_{2}\right.$-IsoPs) have been observed. The measurement of bioactive $F_{2}$-IsoPs levels offers a unique noninvasive analytical tool to study the role of free radicals in physiology, oxidative stress-related diseases, and acute or chronic inflammatory conditions. Measurement of oxidative stress by various other methods lacks specificity and sensitivity. This review aims to shed light on the implemention of $F_{2}$-IsoPs measurement as a gold-standard biomarker of oxidative stress in type 2 diabetics.
\end{abstract}

Key Words: oxidative stress, lipid peroxidation, isoprostanes, type 2 diabetes

\section{Introduction}

"Oxidative stress (OS)" due to the imbalance between pro-oxidant/antioxidant status results in generation of reactive oxygen species (ROS) and subsequent modification of biomolecules such as protein, lipids and nucleic acids. Excessive generation of ROS has been implicated in a variety of pathological events such as diabetes, atherosclerosis, ischemia-reperfusion injury, cardiovascular disease and neurodegenerative disease [1]. Lipid peroxidation (LPO) is the main marker of oxidative stress. Oxidative damage of cellular membranes has been suggested as a common mechanism in a large number of biopathological conditions. It can be measured by either primary or secondary end products of peroxidation. Primary end products of lipid peroxidation include conjugated dienes and lipid hydroperoxides, while secondary end products include thiobarbi-

\footnotetext{
*To whom correspondence should be addressed.

Tel: 60379674953 Fax: 60379674957

E-mail: sekaran@um.edu.my
}

turic reactive substances (TBARS), gaseous alkanes and a group of prostaglandin $(\mathrm{PG}) \mathrm{F}_{2}$-like products termed $\mathrm{F}_{2}-$ isoprostanes $\left(\mathrm{F}_{2}\right.$-IsoPs $)[2,3]$.

Studies have shown that $\mathrm{F}_{2}$-isoprostanes are reliable biomarkers of lipid peroxidation [4] and could therefore, be used as potential indicators of oxidative stress in diverse conditions. Bioactive $\mathrm{F}_{2}$-isoprostanes $\left(8\right.$-Iso- $\left.\mathrm{PGF}_{2 \alpha}\right)$ are regularly formed in various tissues and small amounts can be found in the unmetabolized form in plasma and higher levels in urine in normal basal conditions. Their role in the regulation of normal physiological conditions has yet to be elucidated. This paper reviews the role of $\mathrm{F}_{2}$-IsoPs as novel biomarkers of oxidative stress in relation to type 2 diabetes.

\section{Mechanism of $F_{2}$-IsoPs Formation}

IsoPs are a family of PG-like compounds formed nonenzimatically through free radical catalysed attack on esterified arachidonate followed by enzymatic release from cellular or lipoprotein phospholipids (Fig. 1). IsoPs are formed in situ in the phospholipid domain of cell membranes and circulating lipoproteins. They are then cleaved by 


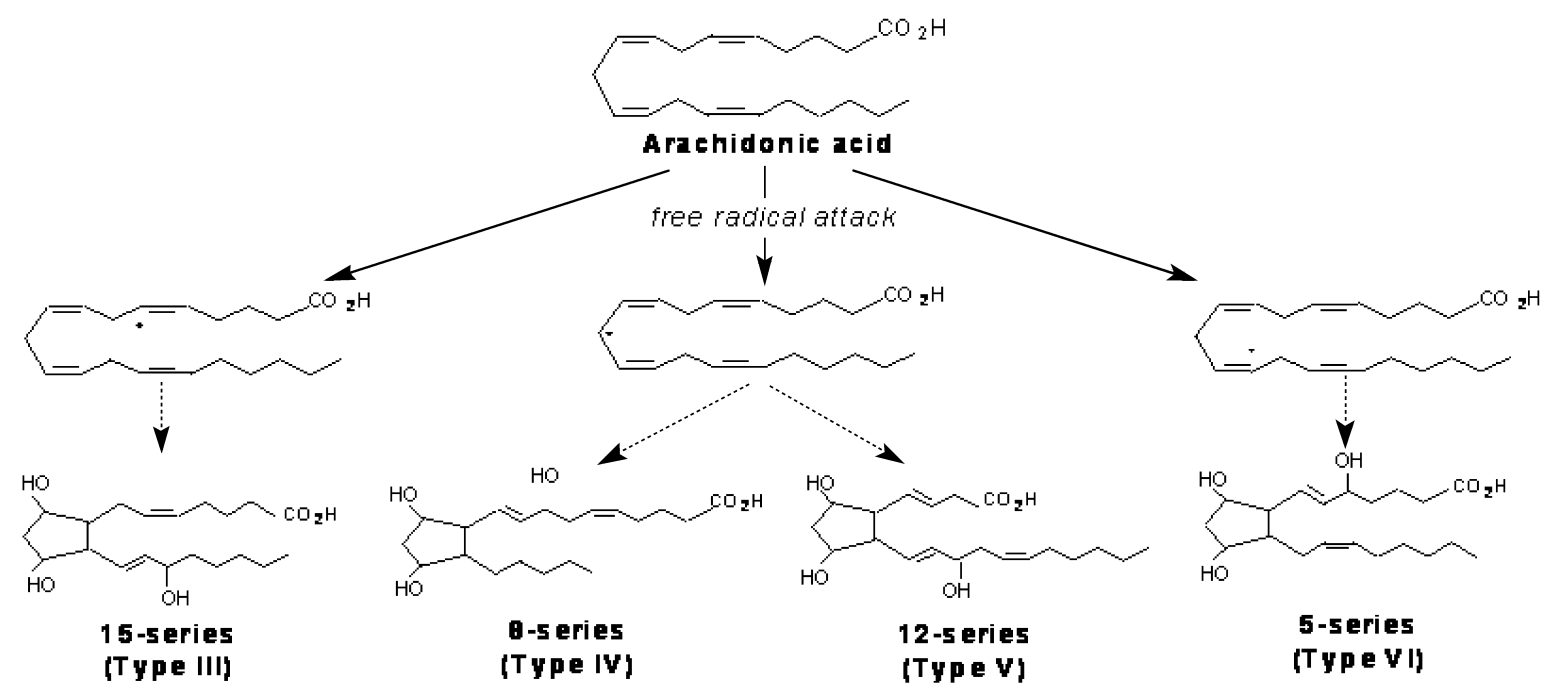

8 dịstereoí om ers including:

8 diastereoĩ omers including:
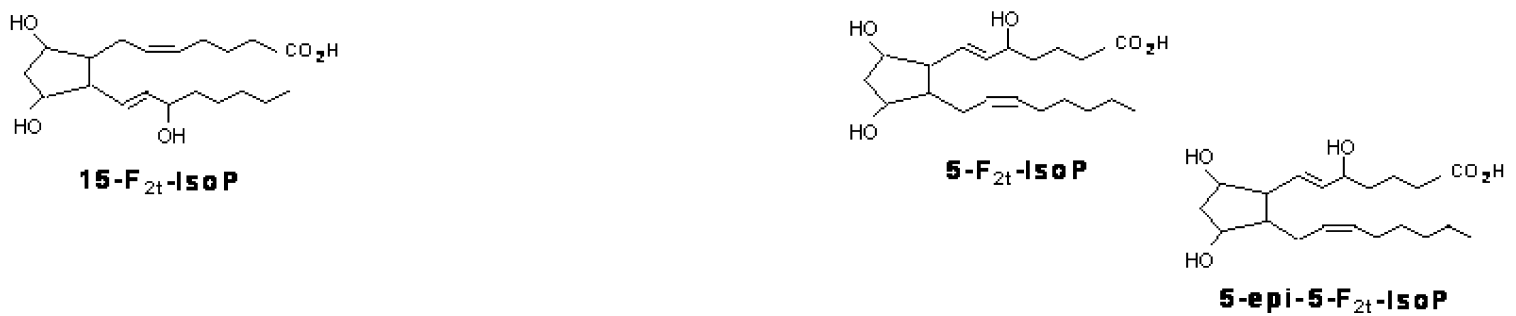

Fig. 1. Formation of $\mathrm{F}_{2}$-Isoprostanes from arachidonic acid, leading to four $\mathrm{F}_{2}$-Isoprostane regioisomers (Adapted from ref. 54)

phospholipases, released extra-cellularly, circulate in blood and are excreted in urine. The measurement of F2-IsoPs, containing the F-type ring analogous to $\mathrm{PGF}_{2 \alpha}$, provides a reliable tool for identifying enhanced rates of lipid peroxidation.

Formation of PG-like compounds during auto-oxidation of polyunsaturated fatty acids was first reported in the mid1970s [5], but isoprostanes were not discovered in humans until 1990 [6]. F2-isoprostanes are a group of 64 compounds isomeric in structure to cyclooxygenase-derived $\mathrm{PGF}_{2 \alpha}$. Other products of the isoprostane pathway are also formed in vivo by rearrangement of labile $\mathrm{PGH}_{2}$-like isoprostane intermediates. These include $\mathrm{E}_{2}$ - and $\mathrm{D}_{2}$-isoprostanes [7], cyclopentenone- $\mathrm{A}_{2}-$ and $\mathbf{J}_{2}$-isoprostanes [8], and the highly reactive acyclic-ketoaldehydes (isoketals) [9] (Fig. 2).

\section{Biological Effects of $\mathrm{F}_{2}$-IsoPs}

The discovery of isoprostanes has important implications for medicine [7]. It has now been established that measurement of $\mathrm{F}_{2}$-isoprostanes is the most reliable approach to assess oxidative stress status in vivo, providing an important tool to explore the role of oxidative stress in the pathogenesis of human disease. In addition, products of the iso- prostane pathway have been found to exert potent biological actions and therefore may be pathophysiologic mediators of disease. IsoPs 8 -iso-PGF $2 \alpha$ and 8 -iso-PGE 2 possess potent biological effects in various systems and they also serve as mediators of oxidant stress through their vasoconstrictive [10] and inflammatory properties. 8 -iso-PGF $2 \alpha$, have been well known to have vasoconstictive effects in various organs including aorta [11], brain [12], cerebral arterioles [13], kidney $[6,10]$, the lung $[14,15]$, pulmonary artery [6], retinal vessels and endothelium [16]. Administration of 8iso-PGF $2 \alpha$ to rabbit induces $\mathrm{COX}$-mediated $\mathrm{PGF}_{2 \alpha}$ formation which has shown to be related to inflammation $[17,18]$.

Isoprostanes induces inflammation and atherogenesis through activation of MAP kinases [19]. Isoprostanes possess important in vitro activities that could be relevant to the pathophysiology of atherosclerosis. It promotes platelet activation [20] and induces mitogenesis in vascular smooth muscle cells [10], stimulates proliferative responses in fibroblasts [21], alters endothelial cell biology as indicated by proliferative effects and increased endothelin-1 expression in bovine aortic endothelial cells [22]. A simplified schematic sketch about its biological effects is shown in Fig. 3 . 
<smiles>[R]C1C(O)CC(O)C1[R]</smiles><smiles>[R]C1C(O)CC(O)C1[R]</smiles><smiles>[R]C1C(O)CC(O)C1O</smiles><smiles>[R]C1OC2CC(O2)C1[R]</smiles><smiles>[R]C(CO)C([R])C(C)O</smiles><smiles>[R]C(CO)C(C)C(C)O</smiles>

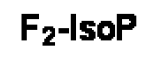<smiles>[R]C1CCC(O)C1[R]</smiles><smiles>[R]C1CCC(O)C1[R]</smiles>

IsoTxA,

$E_{2}$-sok

$D_{2}$-lsoK A2-IsoP $J_{2}-I_{s o P}$<smiles>[R]C1OC(O)CC(O[Tl])C1[R]</smiles>

IsoTxB

Fig. 2. Tx: thromboxane. IsoK: isoketals (Adapted from ref. 55)

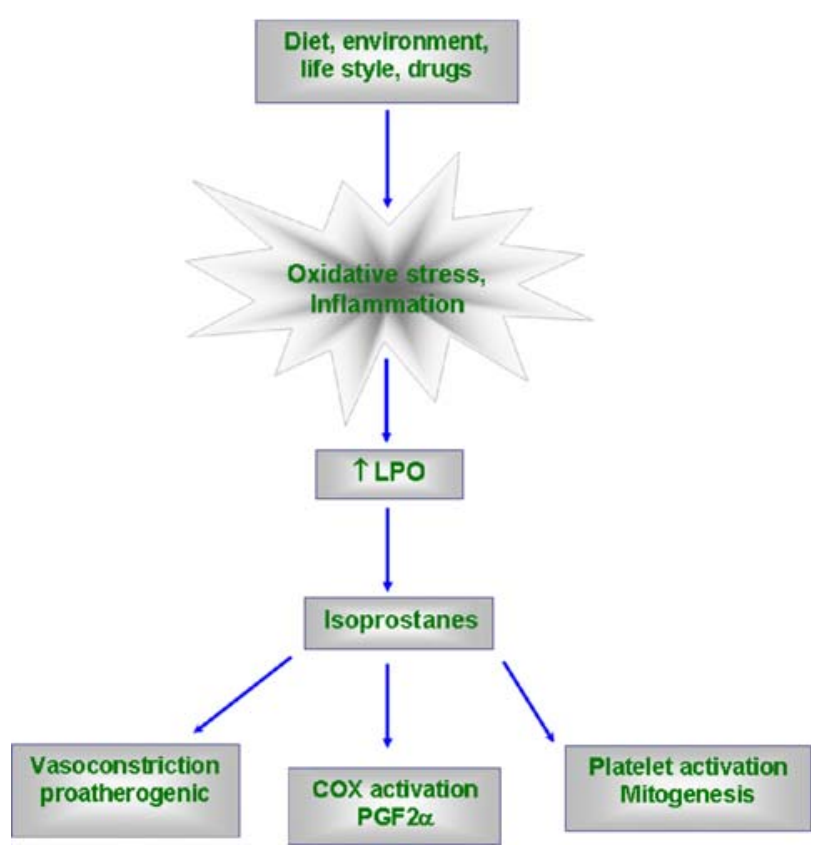

Fig. 3. A simplified sketch showing biological effects of $\mathrm{F}_{2}$ Isoprostanes

\section{Mechanism of Action of F2-IsoPs}

Biological effects of IsoPs are mediated by interaction with receptor. The cyclopentenone-IsoPs such as $\mathrm{PGA}_{2}$ and $\mathrm{PGJ}_{2}$ like compounds, form protein adduct by reacting with glutathione [8]. Isoketals, the byproducts of IsoPs pathway rapidly adduct to lysine residues on proteins and induce cross-linkages [9]. It's still uncertain about the receptors involved in IsoPs actions. The vasoconstricting action is mediated through thromboxane (Tx) receptor antagonists [23]. It acts as antagonist in Tx induced platelet aggregation [24] and induces vasoconstriction in retinal and brain vasculature by endothelial $\mathrm{Tx}$ formation [25].

\section{Metabolism of IsoPs}

IsoPs are produced in situ in their esterified form in tissues and bioconvert first to their free acid form (Fig. 4) and are distributed in both the esterified and free acid form in tissues $[26,27]$. Hydrolytic enzymes that are ubiquitous in the body are primarily responsible for the formation of free isoprostanes from their esterified moiety in the tissues and these are released into the circulation. Pharmacokinetic and metabolic studies revealed the half life of 8 -iso- $\mathrm{PGF}_{2 \alpha}$ to be $\sim 16 \mathrm{~min}$ in humans and $\sim 4 \mathrm{~min}$ in plasma. In vitro and in vivo studies showed that the metabolism of IsoPs occurs through prostaglandins $[28,29]$ and confirms that $\beta$ oxidation is the common degradation pathway in the later step of metabolism of IsoPs.

\section{Biomarkers of LPO and OS}

Oxidation of polyunsaturated fatty acids (PUFA) by free radicals results in excess production of toxic byproducts of peroxidation [30], which is the major underlying mechanism of development of various diseases such as cancer, cardio- 


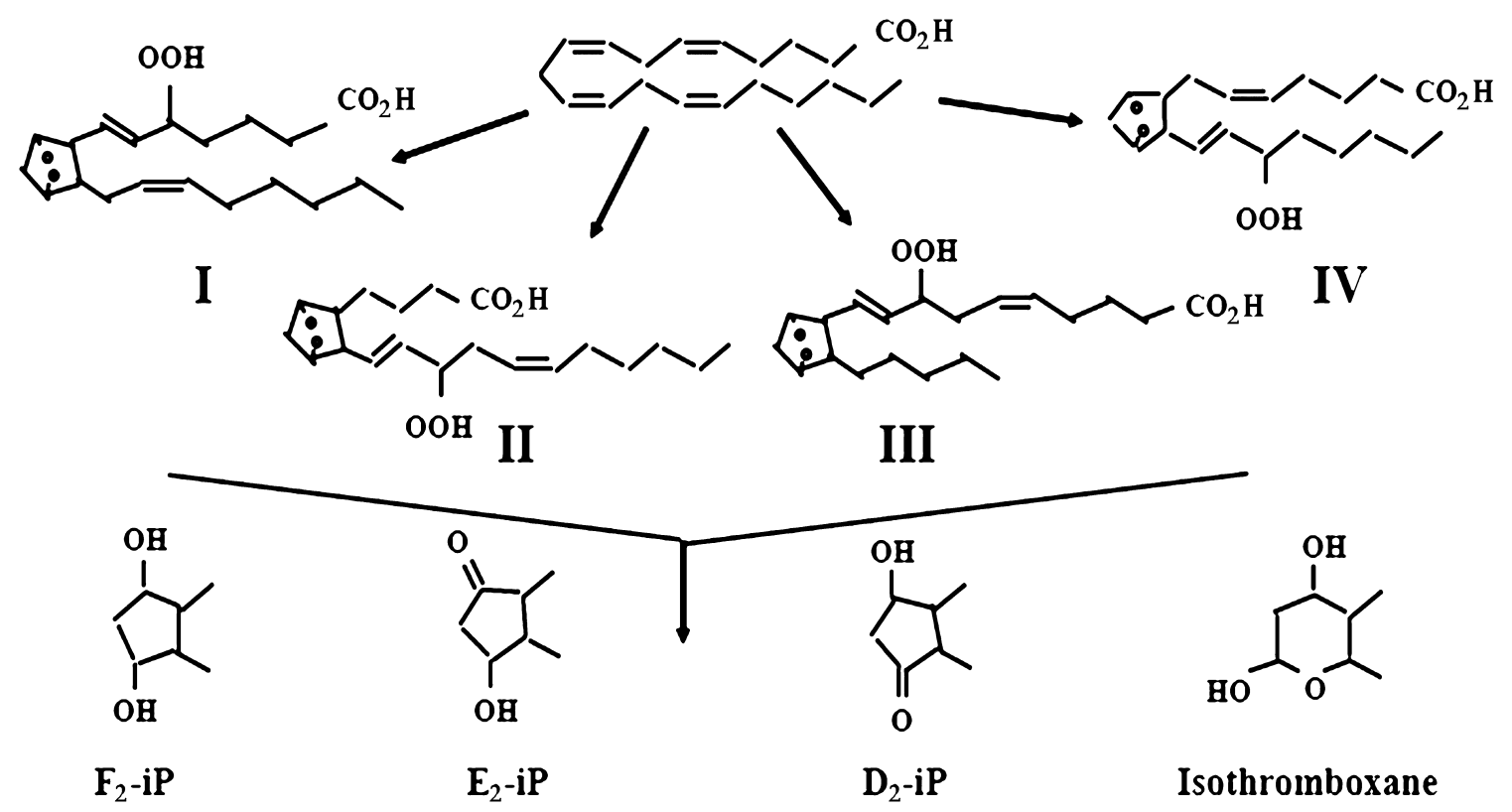

Fig. 4. Formation of free $F_{2}$-Isops from the esterified moiety (Adapted from ref. 56)

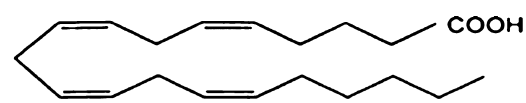

Arachidonic acid

\section{Oxidative stress

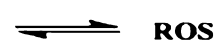

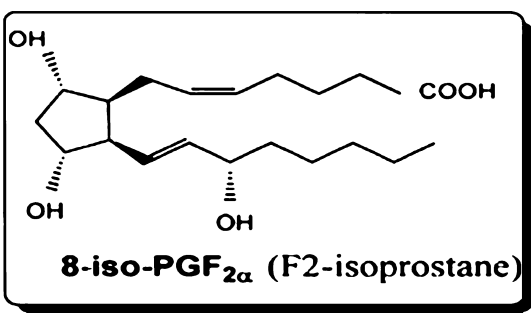

Fig. 5. Biosynthesis of 8-Iso-PGF $2 \alpha\left(\mathrm{F}_{2}-\mathrm{IsoPs}\right)$ (Adapted from ref. 34)

vascular and neurological diseases [1]. There exists a lack of reliable analytical methods for detection of peroxidation in vivo or its end products [2]. A number of studies have revealed the favorable properties of $\mathrm{F}_{2}$-IsoPs as biomarkers for peroxidation and its levels are regarded as the reliable approach for the assessment of peroxidation or OS in vivo $[6,31,32,33,34]$. The schematic diagram of the formation of 8-Iso-PGF $2 \alpha$, a major $\mathrm{F}_{2}$-IsoPs from arachidonic acid is shown in Fig. 5.

\section{IsoPs in Type 2 Diabetes}

OS is implicated in the development of diabetic complications [35] by its association with peroxidation of membrane lipids and LDL-cholesterol. These peroxidation products can impair beta cell function and induce apoptosis [36]. Factors that promote increased oxidative stress in diabetes include antioxidant deficiencies, increased production of ROS, and the process of glycation and glyco-oxidation [35]. The most common antioxidant deficiencies reported in diabetes are lower levels of ascorbate, glutathione and superoxide dismutase [37]. Lower concentrations of reduced glutathione have been documented in diabetic neutrophils and monocytes while lower concentrations of ascorbate have been found in both diabetic plasma and mononuclear cells.

Direct evidence of increased oxidative stress and lipid peroxidation in diabetes has been reported. $\mathrm{F}_{2}$-IsoPs are prostaglandin-like compounds formed in-vivo from free radical catalyzed peroxidation of arachidonic acid and have emerged as novel and direct measures of oxidative stress. IsoPs, derived from the non-enzymatic peroxidation of arachidonic acid are associated with hyperglycemia, vasoconstriction and diabetic nephropathy [38, 39]. F2-Isops, in urine or plasma, provide a highly precise and reliable approach to assess lipid peroxidation in vivo [31]. $\mathrm{F}_{2}$-IsoPs have been found to be increased in both type I and type II diabetes [40]. Increased isoprostane levels were observed in plasma and urine of type 2 diabetes (NIDDM) [40, 38]. Gopaul et al. [40] have reported that 8-iso- $\mathrm{PGF}_{2 \alpha}$ (a major $\mathrm{F}_{2}$-IsoPs) was found to be threefold higher in type 2 
diabetics than in healthy individuals. In addition, increased urinary excretion of 8-iso-PGF $2 \alpha$ was statistically significant in patients with diabetic ketoacidosis [41]. There exists a significant correlation between blood glucose and urinary IsoPs levels, suggesting that peroxidation is related to glycemic control. In vascular smooth muscle cells, F2-IsoPs formation was found to be induced by in vitro by high glucose concentrations [42]. Further, the suggestion that impaired glycemic control is responsible for enhanced formation of $\mathrm{F}_{2}$-IsoPs in type II disease is also supported by the finding that intensive antidiabetic treatment resulted in reductions in blood glucose levels and in urinary IsoP levels [38]. Improved metabolic control of type 2 diabetic patients significantly reduced urinary 8 -iso-PGF $2 \alpha$ levels by $32 \%$. Furthermore improved glycemic control by pancreatic islet transplantation reduces vascular oxidative stress and reverses antioxidant enzyme upregulation in rats with streptozotocin-induced diabetes are consistent with hyperglycemia as the source of oxidative stress [42].

Hyperglycemia, a major common feature of diabetes has been implicated as the source of metabolic derangement. Increase in 8-iso- $\mathrm{PGF}_{2 \alpha}$ was significantly correlated with blood glucose and increased platelet activation. Activation of platelets by hyperglycemia paralleled oxidative stress [43]. These results strongly suggest that increased lipid peroxidation in diabetic patient's leads to the formation of 8 -iso-PGF $2 \alpha$, which, in turn, leads to platelet activation. This is of interest because $\mathrm{F}_{2}$-IsoPs are ligands for the TPx receptor [44]. In another study, levels of esterified. F2-IsoPs in plasma lipids were quantified in 61 patients who underwent coronary angiography. The extent of coronary atherosclerosis in the diabetic patients was similar to that in the 46 nondiabetic individuals. Plasma levels of $\mathrm{F}_{2}$-IsoPs measured in the diabetic patients $(33.4 \pm 4.8 \mathrm{pg} / \mathrm{mL}$, mean $\pm \mathrm{SEM})$ were found to be significantly increased compared with levels measured in the nondiabetic patients $(22.2 \pm 1.9 \mathrm{pg} / \mathrm{mL})$ $(p<0.02)$. Plasma $\mathrm{F}_{2}$-IsoP concentrations were found to be increased by $34 \%$ in acute hyperglycemia and this is similar to other models of oxidative damage. Increased plasma esterified 8-epi-F $2 \alpha$-IsoPs were reported in heavy smokers by Morrow et al. [45]. 8-epi-F2 2 -IsoPs possess biologically important proatherogenic actions, and serves as well as a marker for free radical damage. Under in vitro condition it promotes platelet adhesion to collagen and antagonizes the action of nitric oxide.

Laight et al. [46] recently reported a 5 fold increase in plasma 8-iso-PGF $2 \alpha$, in the obese Zucker rat, a model of insulin resistance. Supplementation of vitamin-E reduced plasma 8-iso-PGF $2 \alpha$ and reversed hyperinsulinemia. Alpha tocopherol therapy significantly decreased oxidative susceptibility of LDL as manifest by prolongation of the lag phase. In both diabetic groups with and without vascular complications the $\mathrm{O}_{2}^{-}$anion release was increased and that this could be attenuated with high dosage alpha tocopherol therapy (1200 IU/RRR-AT). Furthermore, alpha tocopherol therapy resulted in a reduction in IL1- $\beta$, TNF- $\alpha$, IL- 6 and C-reactive protein in the diabetic group.

Hyperglycemia contributes significantly to microvascular disease. The combination of insulin resistance, dyslipidemia, and hypertension contributes to cardiovascular disease (CVD) risk even before glucose intolerance develops. High plasma levels of homocysteine are an independent risk factor for cardiovascular disease [47]. The mechanism by which hyperhomocysteinemia induces atherosclerosis is not fully understood but promotion of LDL oxidation has been suggested. The relationship between total plasma concentrations of homocysteine and $\mathrm{F}_{2}$-IsoPs has been explored [48]. Plasma concentrations of $\mathrm{F}_{2}$-IsoPs increased linearly across quintiles of homocysteine levels. The simple correlation coefficient for association between plasma concentrations of homocysteine and $\mathrm{F}_{2}$-IsoPs was $0.40(p<0.0001)$. The finding of a positive correlation between plasma concentrations of $F_{2}$-IsoPs and homocysteine supports the suggestion that the underlying the link between high homocysteine levels and risk for cardiovascular disease may be enhanced lipid peroxidation.

In accordance with the LDL oxidation hypothesis of atherosclerosis, levels of $\mathrm{F}_{2}$-IsoPs should be higher in atherosclerotic plaques than in normal vascular tissue. To address this issue, levels of $\mathrm{F}_{2}$-IsoPs were measured in fresh advanced atherosclerotic plaque tissue removed during arterial thrombarterectomy $(n=10)$ and compared with levels measured in normal human umbilical veins removed from the placenta immediately after delivery $(n=10)$ [49]. Levels of esterified $\mathrm{F}_{2}$-IsoPs in vascular tissue normalized to both wet weight and dry weight were significantly higher in atherosclerotic plaques compared to normal vascular tissue. A better measure of the actual extent of oxidation, however, may be obtained by normalizing the data to the amount of arachidonic acid present in the tissue since it is the substrate for IsoP formation. When the data was normalized to arachidonic acid content, the $\mathrm{F}_{2}$-IsoP/arachidonic acid ratio was $\sim 4$-fold higher in diseased tissue than the ratio in normal vascular tissue $(p=0.009)$. This finding indicates that unsaturated fatty acids in atherosclerotic plaques are more extensively oxidized than lipids in normal vascular tissue. These observations are also in accord with data from FitzGerald and colleagues who have shown increased amounts of $\mathrm{F}_{2}$-IsoPs in human atherosclerotic lesions and the localization of $\mathrm{F}_{2}$-IsoPs in atherosclerotic plaque tissue to foam cells and vascular smooth muscle cells [50]. While 8 -iso-PGF $2 \alpha$, plays a pivotal role in patients with insulin resistance and hyperglycemia its role is still unclear in subjects without evident hyperglycemia. 


\section{Comprehensive Treatment}

Diabetes-related complications may be limited with much better glycemic control. Good glycemic control can reduce microvascular complications of the eyes, kidneys, and nerves. CVD is the most common and clinically important secondary complication in adults with diabetes [51]. CVD affects up to $80 \%$ of those with diabetes and accounts for approximately $70 \%$ of mortality in diabetes patients. Diabetes increases the risk of CVD 2 to 4 times [52], and the risk is greatest for women [53]. Data suggest that individuals with diabetes have a risk of CVD events that is comparable with that of individuals without diabetes who have preexisting CVD. Abnormalities in blood pressure or lipids will have a greater negative impact on diabetic patients than on those without diabetes. Type 2 diabetes should not be regarded simply as a metabolic syndrome, but as a vascular syndrome with metabolic consequences, including hyperglycemia and insulin resistance. Indeed, type 2 diabetes generally arises in the same metabolic setting as CVD. Obesity, hypertension, dyslipidemia, and insulin resistance are common to both conditions. This fact and the presence of modifiable risk factors in patients with diabetes suggest that early and aggressive treatment can significantly reduce the risk of heart disease hence the requirement for good markers for this disease and its complications.

\section{Conclusion}

OS is the major pathogenic origin for acute and chronic diseases. Available biomarkers for OS are unreliable for assessing the oxidative damage in vivo which results in substandard interpretation of role of OS in various diseases. Current evidences presented above in the review unveil the possibility and reliability of IsoPs as valid biomarkers for the evaluation of OS. Being a bioactive compound it is involved in the normal physiology such as human pregnancy and in the pathology of inflammation. This should help us to explore the role of free radicals in the pathogenesis of human diseases. Further research in this area is necessary to provide insight into the role of OS in human diseases.

\section{Abbreviations}

OS, oxidative stress; LPO, lipid peroxidation; IsoPs, Isoprostanes; ROS, reactive oxygen species; TBARS, thiobarbituric acid reactive substances; PG, prostaglandin; $\mathrm{PGF}_{2} \alpha$, prostaglandin $\mathrm{F}_{2} \alpha$; MAPK, mitogen activated protein kinase; Tx, thromboxane; COX, cyclooxygenase; PUFA, polyunsaturated fatty acid; NIDDM, non-insulin dependent diabetes mellitus.

\section{References}

[1] Halliwell, B. and Gutteridge, J.M.C.: Free radicals in Biology and Medicine, 3rd ed., Clarendon Press, Oxford, 1999.

[2] Halliwell, B. and Grootveld, M.: The measurement of free radical reactions in humans. FEBS Lett., 213, 9-14, 1978.

[3] Morrow, J.D., Harris, T.M., and Roberts, L.J.: Noncyclooxygenase oxidative formation of a series of novel prostaglandins: analytical ramifications for measurement of eicosanoids. Anal. Biochem., 184, 1-10, 1990.

[4] Mezzetti, A., Cipollone, F., and Cuccurullo, F.: Oxidative stress and cardiovascular complications in diabetes: Isoprostanes and new markers on an old paradigm. Cardiovasc. Res., 47, 475-488, 2000.

[5] Pryor, W.A., Stanely, J.P., and Blair, E.: Autoxidation of polyunsaturated fatty acids; II. A suggested mechanism for the formation of TBA-reactive materials from prostaglandinlike endoperoxides. Lipids, 11, 370-379, 1976.

[6] Morrow, J.D., Hill, K.E., Burk, R.F., Nammour, T.M., Badr, K.F., and Roberts, L.J.: A series of prostaglandin F2-like compounds are produced in vivo in humans by a noncyclooxygenase, free radical-catalyzed mechanism. Proc. Natl. Acad. Sci. USA, 87, 9383-9387, 1990.

[7] Morrow, J.D. and Roberts, L.J.: The isoprostanes: unique bioactive products of lipid peroxidation. Prog. Lipid Res., 36, 1-21, 1997.

[8] Chen, Y., Morrow, J.D., and Roberts, L.J. II.: Formation of reactive cyclopentenone compounds in vivo as products of the isoprostane pathway. J. Biol. Chem., 274, 10863-10868, 1999.

[9] Brame, C.J., Salomon, R.G., Morrow, J.D., and Roberts, L.J., II: Identification of extremely reactive $\gamma$-ketoaldehydes (isolevuglandins) as products of the isoprostane pathway and characterization of their lysyl protein adducts. J. Biol. Chem., 274, 13139-13146, 1999.

[10] Takahashi, K., Nammour, T.M., Fukunaga, M., Ebert, J., Morrow, J.D., Roberts, L.J.D., Hoover, R.L., and Badr, K.F.: Glomerular actions of a free radical-generated novel prostaglandin, 8-epi-prostaglandin $\mathrm{F}_{2}$ alpha, in the rat: evidence for interaction with thromboxane $\mathrm{A}_{2}$ receptors. J. Clin. Invest., 90, 136-141, 1992.

[11] Wagner, R.S., Weare, C., Jin, N., Mohler, E.R., and Rhoades, R.A.: Characterization of signal transduction events stimulated by 8-epi-prostaglandin (PG) F2 alpha in rat aortic rings. Prostaglandins, 54, 581-599, 1997.

[12] Hoffman, S.W., Moore, S., and Ellis, E.F.: Isoprostanes: free radical-generated PGs with constrictor effects on cerebral arteries. Stroke, 28, 844-849, 1997.

[13] Hou, X., Roberts, L.J. II., Taber, D.F., Morrow, J.D., Kanai, K., Gobeil, F. Jr., Beauchamp, M.H., Bernier, S.G., Lepage, G., Varma, D.R., and Chemtob, S.: 2,3-Dinor-5,6-dihydro15-F(2t)-isoprostane: a bioactive prostanoid metabolite. Am. J. Physiol. Regul. Integr. Comp. Physiol., R391-R400, 2001.

[14] Banerjee, M., Kang, K.H., Morrow, J.D., Roberts, L.J., and Newman, J.H.: Effects of a novel prostaglandin, 8-epi-PGF2 alpha, in rabbit lung in situ. Am. J. Physiol., 263, H660H663, 1992. 
[15] Bernareggi, M., Rossoni, G., and Berti, F.: Bronchopulmonary effects of 8-epi-PGF2A in anaesthetized guinea pigs. Pharmacol. Res., 37, 75-80, 1998.

[16] Lahaie, I., Hardy, P., Hou, X., Hassessain, H., Asselin, P., Lachapelle, P., Almazan, G., Varma, D.R., Morrow, J.D., Roberts, L.J. 2nd., and Chemtob, S.: A novel mechanism for vasoconstrictor action of 8-isoprostaglandin F2 alpha on retinal vessels. Am. J. Physiol., 274, R1406-R1416, 1998.

[17] Basu, S.: F2-Isoprostane induced prostaglandin formation in the rabbit. Free Radic. Res., 40, 273-280, 2006.

[18] Basu, S.: Radioimmunoassay of 15-keto-13,14-dihydroprostaglandin F2a: an index for inflammation via cyclooxygenase catalysed lipid peroxidation. Prostaglandins Leukot. Essent. Fatty Acids, 58, 347-352, 1998.

[19] Scholz, H., Yndestad, A., Damås, J.K., Waehre, T., Tonstad, S., Aukrust, B., and Halvorsen, P.: 8-isoprostane increases expression of interleukin- 8 in human macrophages through activation of mitogen-activated protein kinases. Cardiovasc. Res., 59, 945-954, 2003.

[20] Patrono, C. and FitzGerald, G.A.: Isoprostanes: potential markers of oxidant stress in atherothrombotic disease. Arterioscler. Thromb. Vasc. Biol., 17, 2309-2315, 1997.

[21] Kunapuli, P., Lawson, J.A., Rokach, J., and FitzGerald, G.A.: Functional characterization of the ocular prostaglandin $\mathrm{F}_{2 \alpha}$ $\left(\mathrm{PGF}_{2 \alpha}\right)$ receptor. Activation by the isoprostane, 12-iso$\mathrm{PGF}_{2 \alpha}$. J. Biol. Chem., 272, 27147-27154, 1997.

[22] Yura, T., Fukunaga, M., Khan, R., Nassar, G.N., Badr, K.F., and Montero, A.: Free-radical-generated $\mathrm{F}_{2}$-isoprostane stimulates cell proliferation and endothelin-1 expression on endothelial cells. Kidney Int., 56, 471-478, 1999.

[23] Audoly, L.P., Rocca, B., Fabre, J.E., Koller, B.H., Thomas, D., Loeb, A.L., Coffman, T.M., and FitzGerald, G.A.: Cardiovascular responses to the isoprostanes iPF2 $\alpha$-III and iPE2-III are mediated via the thromboxane $A_{2}$ receptor in vivo. Circulation, 101, 2833-2840, 2000.

[24] Morrow, J.D., Minton, T.S., and Roberts, L.J., II: The F2-isoprostane, 8-epi-prostaglandin F2 $\alpha$, a potent agonist of the vascular thromboxane/endoperoxide receptor, is a platelet thromboxane/endoperoxide receptor antagonist. Prostaglandins, 44, 155-163, 1992.

[25] Hou, X., Gobeil, F. Jr, Peri, K., Speranza, G., Marrache, A.M., Lachapelle, P., Roberts, L.J. II., Varma., D.R., and Chemtob, S.: Augmented vasoconstriction and thromboxane formation by 15 -F2t-isoprostane (8-iso-PGF2 $\alpha$ ) in immature pig periventricular brain microvessels. Stroke., 31, 516-525, 2000.

[26] Sodergren, E., Vessby, B., and Basu, S.: Radioimmunological measurement of F2-isoprostanes after hydrolysis of lipids in tissues. Prostaglandins Leukot. Essent. Fatty Acids, 63, 149$152,2000$.

[27] Morrow, J.D., Awad, J.A., Boss, H.J., Blair, I.A., and Roberts, L.J. II.: Non-cyclooxygenase derived prostanoids (F2-isoprostanes) are formed in situ on phospholipids. Proc. Natl. Acad. Sci. USA, 89, 10721-10725, 1992.

[28] Basu, S.: Metabolism of 8-iso-prostaglandin $\mathrm{F}_{2 \alpha}$. FEBS Lett., 428, 32-36, 1998.

[29] Basu, S.: Metabolism of 8-iso-PGF2a in the rabbit.
Prostaglandins Leukot. Essent. Fatty Acids, 428, 32-36, 1998.

[30] Halliwell, B.: Free radicals, antioxidants, and human disease: curiosity, cause, or consequence? Lancet., 10, 721-724, 1994.

[31] Roberts, L.J. II. and Morrow, J.D.: Measurement of F2isoprostanes as an index of oxidative stress in vivo. Free Radic. Biol. Med., 28, 505-513, 2000.

[32] Cracowski, J.L., Durand, T., and Bessard, G.: Isoprostanes as a biomarker of lipid peroxidation in humans: physiology, pharmacology and clinical applications. Trends Pharmacol. Sci., 135, 360-366, 2002.

[33] Lawson, J.A., Rokach, J., and FitzGerald, G.A.: Isoprostanes: formation analysis and use of indicies of lipid peroxidation in vivo. J. Biol. Chem., 27, 24441-24444, 1999.

[34] Basu, S.: Carbon tetrachloride induced lipid peroxidation: eicosanoid formation and its regulation by antioxidants. Toxicology, 189, 113-127, 2003.

[35] Baynes, J.W.: Role of oxidative stress in development of complications in diabetes. Diabetes, 40, 405-412, 1991.

[36] Miwa, I., Ichimura, N., Sugiura, M., Hamada, Y., and Taniguchi, S.: Inhibition of glucose-induced insulin secretion by 4-hydroxy-2-nonenal and other lipid peroxidation products. Endocrinology, 141, 2767-2772, 2000.

[37] Oranje, W.A. and Wolffenbutte, B.H.: Lipid peroxidation and atherosclerosis in type II diabetes. J. Lab. Clin. Med., 134, 19-32, 1992.

[38] Davì, G., Ciabattoni, G., Consoli, A., Mezzetti, A., Falco, A., Santarone, S., Pennese, E., Vitacolonna, E., Bucciarelli, T., Costantini, F., Capani, F., and Patrono, C.: In vivo formation of 8-iso-prostaglandin f2alpha and platelet activation in diabetes mellitus: effects of improved metabolic control and vitamin E supplementation. Circulation, 99, 224-229, 1999.

[39] Mezzetti, A., Cipollone, F., and Cuccurullo, F.: Oxidative stress and cardiovascular complications in diabetes: isoprostanes as new markers on an old paradigm. Cardiovasc. Res., 47, 475-488, 2000.

[40] Gopaul, N.K., Anggård, E.E., Mallet, A.I., Betteridge, D.J., Wolff, S.P., and Nourooz-Zadeh, J.: Plasma 8-epi-PGF2 alpha levels are elevated in individuals with non-insulin dependent diabetes mellitus. FEBS Lett., 368, 225-229, 1995.

[41] Catella-Lawson, F., Kapoor, S., Pratico, D., Braunstein, S.N., Caraballo, V., and FitzGerald, G.A.: Oxidative stress and diabetes mellitus. J. Invest. Med., 44, 223A, 1996. Abstract.

[42] Natarajan, R., Lanting, L., Gonzales, N., and Nadler, J.: Formation of an $\mathrm{F}_{2}$-isoprostane in vascular smooth muscle cells by elevated glucose and growth factors. Am. J. Physiol., 271, H159-H165, 1996.

[43] Davì, G., Gresele, P., Violi, F., Basili, S., Catalano, M., Giammarresi, C., Volpato, R., Nenci, G.G., Ciabattoni, G., and Patrono, C.: Diabetes mellitus, hypercholesterolemia, and hypertension but not vascular disease per se are associated with persistent platelet activation in vivo. Evidence derived from the study of peripheral arterial disease. Circulation, 96, 69-75, 1997.

[44] Fam, S.S. and Morrow, J.D.: The isoprostanes: unique products of arachidonic acid oxidation-a review. Curr. Med. Chem., 10, 1723-1740, 2003.

[45] Morrow, J.D., Frei, B., Longmire, A.W., Gaziano, J.M., 
Lynch, S.M., Shyr, Y., Strauss, W.E., Oates, J.A., and Roberts, L.J. 2nd.: Increase in circulating products of lipid peroxidation (F2-isoprostanes) in smokers. Smoking as a cause of oxidative damage. N. Engl. J. Med., 332, 11981203, 1995.

[46] Laight, D.W., Desai, K.M., Gopaul, N.K., Anggård, E.E., and Carrier, M.J.: F2-isoprostane evidence of oxidant stress in the insulin resistant, obese Zucker rat: effects of vitamin E. Eur. J. Pharmacol., 377, 89-92, 1999.

[47] Boushey, C.J., Beresford, S.A., Omenn, G.S., and Motulsky, A.G.: A quantitative assessment of plasma homocysteine as a risk factor for vascular disease. Probable benefits of increasing folic acid intakes. JAMA, 274, 1049-1057, 1995.

[48] Voutilainen, S., Morrow, J.D., Roberts, L.J., Alfthan, G., Alho, H., Nyyssonen, K., and Salonen, J.T.: Enhanced in vivo lipid peroxidation at elevated plasma total homocysteine levels. Arterioscler. Thromb. Vasc. Biol., 19, 1263-1266, 1999.

[49] Gniwotta, C., Morrow, J.D., Roberts, L.J., and Kuhn, H.: Prostaglandin F2-like compounds, F2-isoprostanes, are present in increased amounts in human atherosclerotic lesions. Arterioscler. Thromb. Vasc. Biol., 17, 3236-3241, 1997.

[50] Pratico, D., Iuliano, L., Mauriello, A., Spagnoli, L., Lawson, J.A., Rokach, J., Maclouf, J., Violi, F., and FitzGerald, G.A.:
Localization of distinct F2-isoprostanes in human atherosclerotic lesions. J. Clin. Invest., 100, 2028-2034, 1997.

[51] Haffner, S.M., Lehto, S., Ronnemaa, T., Pyörälä, K., and Laakso, M.: Mortality from coronary heart disease in subjects with type 2 diabetes and in nondiabetic subjects with and without prior myocardial infarction. N. Engl. J. Med., 339, 229-234, 1998.

[52] Kannel, W.B. and McGee, D.L.: Diabetes and glucose tolerance as risk factors for cardiovascular disease: The Framingham Study. Diabetes Care, 2, 120-126, 1979.

[53] Sowers, J.R.: Diabetes mellitus and cardiovascular disease in women. Arch. Intern. Med., 158, 617-621, 1998.

[54] Marlière, S., Cracowski, J.L., Durand, T., Chavanon, O., Bessard, J., Guy, A., Stanke-Labesque, F., Rossi, J.C., and Bessard, G.: The 5-series $\mathrm{F}(2)$-isoprostanes possess no vasomotor effects in the rat thoracic aorta, the human internal mammary artery and the human saphenous vein. $\mathrm{Br}$. J. Pharmacol., 135, 1276-1280, 2002.

[55] Montuschi, P., Barnes, P.J., and Roberts, L.J. 2nd.: Isoprostanes: markers and mediators of oxidative stress. FASEB J., 18, 1791-1800, 2004.

[56] Patrignani, P. and Tacconelli, S.: Isoprostanes and other markers of peroxidation in atherosclerosis. Biomarkers, $\mathbf{1 0}$, S24-S29, 2005. 